\title{
Psychiatric Issues in Pediatric Organ Transplantation
}

\author{
Margaret L. Stuber, MD \\ Jane and Marc Nathanson Professor of Psychiatry, David Geffen School of Medicine at UCLA, Los \\ Angeles, California
}

\section{Synopsis}

Solid organ transplantation has become the first line of treatment for a growing number of lifethreatening pediatric illnesses. With improved survival, research into the long-term outcome of transplant recipients has become important to clinicians. Adherence to medical instructions remains a challenge, particularly in the adolescent population. New immunosuppressant approaches promise to expand organ transplantation in additional directions. Extension of transplantation into replacement of organs such as faces and hands raises complex ethical issues.

\section{Keywords}

child; adolescent; transplant; psychiatric

The field of solid organ transplantation has grown enormously since 1983, when the widespread availability of effective immunosuppression made what had been surgically possible a viable clinical reality. In the United States 23, 846 solid organ transplants were performed between January and October 2009 (1). As of January 18, 2010 there were 105, 239 people listed as awaiting transplants in the United States (1). This paper will discuss the types of transplants now commonly done for children, assessment and support of children and families undergoing transplantation, the long-term impact of organ transplantation on children, and new developing areas in organ transplantation.

\section{Background}

Pediatric solid organ transplants are still relatively rare. Less than $8 \%$ of the recipients of solid organ transplants in the United States annually are under 18 years of age, according to the 2008 report from the OPTN/SRTR (1). The annual number of pediatric solid organ transplants has been approximately 2000 children since 1998. Although the wait for an organ that is a match for size as well as blood type may be longer for young children, the 5 year survival is similar in children to that of young adults(1). (Table $1 \&$ Table 2).

Immunosuppression is the critical element in survival of most solid organ transplant recipients $(2,3)$. Organs vary as to their levels of immune activity, and subsequently some require more exact matching with the donor and more or different types of immunosuppression. Kidney transplants proved to be feasible in identical twins (for whom immunosuppression was not

\footnotetext{
(c) 2010 Elsevier Inc. All rights reserved.

Corresponding author: Margaret L. Stuber, MD, mstuber@mednet.ucla.edu, Telephone: 310 825-5213, Fax: 310 206-4446, Mailing address: 760 Westwood Plaza, Semel Institute, room 48-240, Los Angeles, CA 90024-1759.

Publisher's Disclaimer: This is a PDF file of an unedited manuscript that has been accepted for publication. As a service to our customers we are providing this early version of the manuscript. The manuscript will undergo copyediting, typesetting, and review of the resulting proof before it is published in its final citable form. Please note that during the production process errors may be discovered which could affect the content, and all legal disclaimers that apply to the journal pertain.
} 
needed) as early as the 1950s (4). In the 1960s, non-twin transplants of kidneys were successful using a combination of azathioprine and prednisone (5). However, even with immunosuppression, liver transplants almost always resulted in rejection until the introduction of cyclosporine in 1983 (6). Since then, tacrolimus and sirolimus have added options for organ transplantation immunosuppression, and have led to decreased use of prednisone, azathioprine and cyclosporine (7). However, posttransplant lymphoproliferative disease, nephrotoxity, and denovo autoimmune hepatitis remain as possible complications of these medications, in addition to the usual risks of decreased immune function (8). The growth problems associated with chronic steroids have led to attempts to reduce or remove it as a component in immunosuppression regimens for pediatric recipients (9).

\section{Kidney}

Kidney transplants were the earliest of the solid organ transplants to be successful, and they continue to have the best long-term survival (1). Today the five year survival for pediatric kidney transplants is over 90 percent. There are several reasons for the advantage kidney transplantation has over other solid organ transplants.

1. There is a mechanical alternative to transplantation, dialysis, which can keep a person alive while awaiting a matched organ. Hemodialysis requires visits to an outpatient center three times a week, for hours at a time, and peritoneal dialysis requires connection to an elaborate, sterile set of equipment in the home for 10 hours a night. Patients receiving dialysis must still watch their salt intake, and the intermittent nature of the dialysis cannot replicate the constant detoxification of a working kidney. Both types of dialysis have risks, and impact a patient's work and social life. However, dialysis is the reason that with kidney transplantation graft failure is not usually equivalent to recipient death (10).

2. Kidneys are paired organs, and humans can generally function quite well with just one kidney. This has meant that living-related kidney donation has been possible. Using relatives as donors allows better immunological matching, and therefore decreased risk of rejection. It also means the donated organ is taken from a healthy person, and is available when the recipient needs it, not when a matched cadaver is found. Although kidney donation is a major surgical procedure, the risk to the donor is relatively small.

The fact that kidneys are paired organs also means that two recipients can receive organs from one cadaver donor. This has helped to decrease the waiting list, relative to other types of solid organ transplants. Anything that decreases the wait time improves the outcome of the surgery, by allowing the recipient to be healthier at the time of transplant (11).

3 Kidneys are less immune active than some other organs. Although matching of organs by blood type ( $\mathrm{A}, \mathrm{B}, \mathrm{AB}$ or $\mathrm{O}$ ) and $\mathrm{Rh}$ factor (negative or positive) is important, the more specific HLA typing used for liver and heart transplants seems to be less important in graft rejection for kidney transplants. The difference in 10year deceased donor kidney survival between the best and worst HLA-matched combinations was $10 \%$, with half-lives ranging from 11.6 years to 8.6 years (12). Indeed, some renal transplant recipients have been able to get off immunosuppressant medication altogether (13).

$4 \quad$ Most pediatric kidney transplants are done in children over the age of 6 years (1). This is partly due to the illnesses which lead to kidney failure in the pediatric population, and partly due to the option of dialysis. This allows larger organs to be used than would be possible in younger and smaller children, expanding the number of potential donors. 
A result of these differences is that kidney transplantation has been practiced since the 1950s, and is thus well-established at many centers. More programs are authorized to provide kidney transplants as more have had and continue to have the required number of procedures to be considered "expert". The number of kidney transplants in adults related to diabetic nephrology led to combined pancreas and kidney transplants, primarily in adults. These are now quite successful, with a one year graft survival of $85 \%$ and three year patient survival of $90 \%$ (14). Joint kidney and liver transplants are also relatively common (15).

\section{Liver}

Liver transplantation does not have many of the advantages listed above for kidney transplantation. There is no mechanical substitute for the liver, and the liver is not a paired organ. The liver is active immunologically, and must be matched carefully to prevent rejection. The majority of liver transplants in children are done on children under the age of five years, and most of these are for congenital illness, such as alpha 1 antitrypsin or biliary atresia (16). Thus the children are quite small, and cannot accommodate an adult liver.

However, the liver is an organ with individual lobes, and people can survive with less than a complete functional liver. Thus, for the reasons described above, once the surgical techniques were found to be feasible, partial livers were used for children. Removing just one lobe of the liver allowed the donor to continue a health life, allowed better-matched relative to be donors, produced a smaller organ to fit young children, and gave an option to children who would not survive the wait for a deceased donor (17).

One problem with this was the coercion inherent in being a potential living related donor. This had, of course, also been an issue for kidney transplantation. However, the availability of dialysis reduced some of the time urgency and increased the likelihood of finding another donor. For parents of very small children in liver failure there were very few options. Programs responded to this by requiring careful assessments of potential donors to see that they qualified as giving true informed consent. That is, they needed to understand the problem, the various alternative treatments (including doing nothing) and the potential consequences of each option, and to be deciding without undue influence. In reality, it was extremely rare for parents to feel comfortable refusing to be a donor.

Living related partial liver donation is now uncommon except in areas with little access to deceased donor organs (18). Although the mortality was very low for donors, it was not zero, and the morbidity could be significant, if only in the loss of a month of employment. New techniques to use one cadaver liver for multiple recipients made the use of parental donors less necessary (19).

Although liver transplantation is done at major centers all over the world, it is sufficiently specialized that not all medical centers have programs. To maintain a contract with the United Network for Organ Sharing, which oversees distribution of organs, a center has to perform a minimum number of transplants, and meet criteria on survival, complications, and services provided. Liver transplantation is therefore usually done at a regional center, with long-term follow-up coordinated though the regional center at the local hospital or clinics (20).

\section{Heart}

Hearts are neither paired nor lobed, and are very immunologically active. But it was an unexpected aspect of heart transplantation which has led to some of the most serious concerns about pediatric heart transplants. Although initial survival was excellent, and improving technique led to dramatic improvements in 1-yr survival following cardiac transplantation, long-term graft survival has been limited by what is called accelerated transplant coronary 
artery disease or cardiac graft vasculopathy. This is an immunologically mediated chronic rejection characterized by progressive fibroproliferative disease, resulting in intimal thickening and occlusion of the grafted coronary vessels (21). Lipid accumulation in allograft arteries is prominent, with lipoprotein entrapment in the subendothelial tissue, through interactions with proteoglycans (22). The hope that a pediatric organ transplant recipient could have just one transplant and live with that heart for his or her normal life expectancy is lessened by evidence that significant atherosclerotic disease can be seen in as few as five years. This is an area of intense research (23).

\section{Lung and heart/lung}

Cystic fibrosis is one of the most common indications for lung transplantation worldwide and certainly the most common indication for all pediatric lung transplants and for bilateral lung transplantation irrespective of age (24). Outcomes are outstanding when compared with other indications for lung transplantation, and an increasing number of centers now report mean survival of greater than 10 years posttransplant (1).Pediatric lung or heart/lung transplantation is also done for treatment of congenital heart disease, primary pulmonary hypertension, or pulmonary fibrosis, and has not generally been done for very young children. Bronchiolitis obliterans remains the major late complication (25). The survival has not been as good as with liver and heart transplants, but has been improving, at least for some underlying illnesses (26). Reduced size transplantation has proven to be successful, allowing smaller children to be transplanted despite the scarcity of small donors (27).Combined heart and lung transplant is comparable in success to lung transplantation (28).

\section{Small bowel or Multivisceral}

Transplantation of the small bowel is done when the intestine cannot provide the body with sufficient nutrition or hydration. The most common reasons for intestinal failure in children are necrotizing enterocolitis, gastroschisis, intestinal atresia, volvulus, psycho-obstruction, and aganglianonsis. Although short-gut syndrome, secondary to surgical correction of the conditions listed above, is the most common cause of intestinal failure, short intestinal length is neither necessary nor sufficient to require transplantation (29). Transplantation of the small bowel in children had a high initial rate of complications, resulting in a relatively low five year survival (30). Although the 1 year survival in adults is now comparable to that of liver and heart transplants, the survival in children is still much less nationally (1). However, specific centers report 1 and 5 year survival rates of $90 \%$ and $77 \%$ respectively (30). Transplantation of the small bowel has been used in cases where parenteral nutrition had failed (29).

Multivisceral grafts can include donor spleen and large intestine as well as small bowel. These patients frequently require intensive care preoperatively and have unique intensive care needs postoperatively (31). With increasing survival rates, intestinal transplantation and multivisceral transplantation have reached the mainstream of medical care. Indications now include neoplastic disease, extensive splanchnic thrombosis and abdominal catastrophes (32). Living donor intestinal transplantation is also being explored as an alternative to minimize death on the waitlist (33).

\section{Transplant evaluations}

Organs for transplantation are a scarce resource, and so allocation is carefully monitored and regulated. Teams of physicians from a variety of specialties assess a candidate to ascertain if the patient is sick enough to need a transplant, well enough to survive the transplant, and able to follow the medical instructions necessary to keep the graft alive. Once the patient has been listed as a good candidate, priority is given to the sickest person in the region on the list who matches the donor organ. The list must be regularly updated to remove anyone who is too sick, lest an organ be "wasted". The role of the psychiatrist in transplantation with adults is primarily 
focused on evaluation for suitability for the list. The psychiatrist generally serves to determine if there are reasons to think the patient will be non-adherent. In addition to frank psychopathology, a history of smoking, illicit drugs or alcohol abuse requires particular care (34).

For most pediatric candidates, who are quite young, nonadherence assessment focuses primarily on the parents. This assessment is often done by social workers rather than psychiatrists or psychologists. Referral for a psychiatric assessment in pediatric organ transplantation is primarily done with adolescents. A Pediatric Transplant Rating Instrument has been developed to be used in these settings, which assesses the following domains (35):

1. Knowledge and motivation regarding the transplant

2. History of adherence with medications, appointments, and risks for nonadherence

3. Patient and parental psychiatric and substance abuse history

4. Parental supervision, family conflict and communication style

5. Financial, logistical and psychosocial support

6. Relationship with the medical team

Child psychiatrists or psychologists may also be asked to assess someone as a potential candidate for solid organ transplantation in the following situations.

Suicide attempt The classic version of this situation would be a teenager who has taken a handful of acetaminophen, and is in acute liver failure. In this case, it is possible that the acute injury will resolve without need for transplantation, but the assessment must be done while the patients is alert, before hepatic encephalopathy makes it impossible to assess the situation adequately. The primary goal of this assessment is to determine whether or not this was a serious suicide attempt, or a gesture which is unlikely to be repeated. A careful history and mental status exam, with collaboration from family members, can usually determine if this is a teen with a chronic psychiatric problem. In most cases the psychiatric assessment in the case of a suicide attempt is advisory, guiding the posttransplant care, rather than advising against placing on the list.

Need for a "family transplant" Some unfortunate children have chaotic family situations as well as a life-threatening illness. This would include the young teen with hepatitis from rape by her step-father, or an older teen with a viral endocarditis from his heroin dealer mother. Although the odds that these children will be non-adherent later on are relatively high, it is difficult for many teams to condemn them to death for the results of the sins of their parents. The immediate need is to find them a safe place and support system for the pre-transplant waiting period. This can be difficult, as these children generally require more medical care than can be provided in regular foster care settings. Even more difficult is helping these children with long-term survival. The evidence to date suggests that problematic early childhoods are predictive of poor adherence (36). The family is an important component of transplant success (37).

\section{Pretransplant psychiatric considerations}

Most of the psychiatric and psychological issues in the pretransplant phase of care are familiar to the Consultation-liaison child psychiatrist as they are similar to those seen in families dealing with other life-threatening childhood illnesses (38). 


\section{Guilt}

Guilt can be a significant issue for parents of infants who are struggling with a genetic illness, usually previously unknown to them. It is also an issue for people whose children have infectious diseases, particularly if it is associated with travel. However, the parental wish to protect their children from all that is harmful means that some feelings of guilt will almost always be present.

\section{Anger and blame}

When people want to find a reason for something that is apparently random, they can turn to guilt or blame, or a mixture of the two. Anger and blame can be quite generalized or very specific, with parents most commonly blaming each other or one or more of the doctors they have seen.

\section{Depression and helplessness}

Parents typically will be advocates for their ill or hospitalized children. However, in some cases the parents withdraw. This does not necessarily mean that they don't care about their children, although often staff will interpret this as abandonment.

The best intervention for all of the problems above is obviously a quick and successful transplant. However, given the lengthy time that many children are on the list awaiting a transplant, some work is often necessary to help the parents deal with their guilt, anger and helplessness, and for the staff to deal with what look to them like difficult parents. Particularly problematic are the parents who deal with their own emotional distress by trying to take control. This can range from parents who will only allow certain people in the child's hospital room, to those who actually readjust settings on intravenous drips or ventilators. Setting up limits, while acknowledging the parents need for some control in an overwhelming situation, requires work with the entire extended treatment team, but can be very effective (39).

For less problematic but distressed parents, helping them find and use a social support network can be very helpful. Some transplant programs will have groups for parents. Internet based programs can also be helpful. An example is the Experience Journal (experincejournal.org) (40). This very user-friendly website has stories written by parents and children dealing with pediatric liver transplantation and congenital heart disease, as well as interviews with doctors and other medical information.

\section{Transplant hospitalization}

The actual transplant is usually a surprise. After days to months of waiting, there is a sudden disruption of life. It is exciting, but frightening. This is amplified if there is a living-related donor. In such cases, there are two family members who are at risk during the surgery, and two to support afterward. For very young children, who do not understand the concept of shortterm pain for long-term gain, the transplant hospitalization, pain, procedures, and intensive care unit, can be quite traumatic. Other children may not be able to appreciate that this hospitalization will be different than others.

Transplant hospitalizations can be quite brief, given the major surgery and the usually lengthy illness which preceded it. However, there are often complications. What a surgeon considers minimal, such as a return to the OR to deal with a small bleed, may feel overwhelming to the family or child. Although everyone is warned otherwise, there is usually some hope that the transplant will result in immediate improvement in the child's condition. Children do respond quickly, and many are out of intensive care in days after an organ transplant. However, there is often a rocky course initially, particularly if the child has been very seriously ill. Parents 
during this time are well-advised to utilize their extended families and other social support networks (41).

\section{Post-transplant}

The first year post-transplant is often difficult. Children and parents learn that they have traded a life-threatening illness for a chronic condition, which requires daily medications, regular doctor visits, and care regarding exposure to infectious disease. In addition, it is likely that they will experience at least one episode of rejection as the medical team is adjusting their immunosuppressant regime. Not all recipients will be hospitalized during the year after transplantation, but many will. A qualitative study of pediatric heart transplant recipients found that the limitations on their activities with friends, family and at school were seen as major obstacles to quality of life by pediatric transplant recipients (42).

Family must also make adjustments. Children who have been seen as fragile must gradually be allowed to encounter normal developmental challenges. Parents (and school personnel!) may be reluctant to allow children to return to school, physical activities, and play with friends. Parents are challenged to find a new equilibrium to be safe but not over-protective as the child re-enters the growth curve (43). Parents often underestimate the impact of the transplant on the child, focusing on how much healthier the child is and not noticing how depressed the child may have become (44).

One question for families is who will oversee the medication. With very young children it is obvious that parents must assume responsibility for ordering, obtaining, and administering the medication. For a parent to say that a two year old "doesn't want to take the medication" is understandable, but is not an acceptable reason for the child to not be receiving the necessary immunosuppressant medications. However, as children get older they should be assuming more responsibility for their lives, including self care. Surveys have shown that at about 9 years children start taking on some ownership of their medication regimens (45). That is, at this age children start taking the medication on their own, rather than taking it when given to them by parents. Parents are still responsible for monitoring when more medications are needed, calling in prescriptions and picking up the medications. They may also check with the child to make sure the medication has been taken. As children get older, more of the tasks associated with medication self-care can and should be taken on, with parental monitoring.

This transition can be daunting to both parents and children. However, the alternatives are problematic. The child who takes on no responsibility until adolescence is likely to see the medications as something outwardly imposed by adults, and is more likely to resist them. But even if the teen is passively compliant this does not prepare them well for the eventual transition to care by an internist rather than a pediatrician. Pediatricians and their offices are more likely to follow-up on a patient who does not make, cancels, or does not show up for appointments than are offices who work with adult patients. Studies have shown that this transition can be difficult for children and adolescents with chronic conditions (46). One approach to this has been to have pediatric practices continue to follow teens until their mid-20s, when most are functioning independently (47). Other programs have created transition clinics for teens and young adults, which specifically focus on helping young people take control of their own health care (48).

\section{Adherence}

One of the most complicated problems in all types of pediatric transplants is that of nonadherence to medical instruction. Although some types of transplant, such as heart transplants, have specific expectations in terms of diet and exercise, consistent use of immunosuppression is the primary behavioral challenge to survival after organ transplantation. 
Non-adherence with medications is very common, with studies repeatedly demonstrating that only about half of people prescribed medication take at least $80 \%$ of the medications as prescribed (49). The complexity of the regimen is associated with the likelihood of adherence, such that medications which must be taken several times a day, or in specific relationship to food or milk are less likely to be taken regularly(50). Medications which have adverse effects are less likely to be taken, but so are medications which are largely preventative, and have no immediate adverse impact when they are not taken. An example is antihypertensive medications, which can cause sexual side-effects, and often create no immediate perceivable adverse effects when stopped.

It is often surprising to physicians that a transplant recipient would ever stop immunosuppressant medications. After all, they have been saved from death by this transplant. Why would they do anything to risk it? The reasons are multiple.

1. As mentioned above, complex regimens are the most likely to lead to poor adherence. Immunosuppressant regimens almost always involve more than one medication, taken more than once a day. Medications which can be paired with a morning or evening regimen are simpler than those which need to be taken at school. Students are almost never allowed to carry medication with them at school, and must go to the nurse's office to get the medication. This increases the probability that the student will not remember, or will try to avoid the embarrassment of a trip to the nurse's office.

2. Medication which causes adverse effects is less likely to be taken. The weight gain and impact on the face and abdomen associated with steroids makes these quite aversive to children and adolescents. Cyclosporine can lead to increased gum growth, and darker, thicker arm hair, which are of cosmetic concern. Recipients learn that these effects diminish if they reduce or stop their medication.

3. Recipients who decrease or stop their medications also find that there are no immediate adverse consequences. Indeed, it turns out that some recipients can successfully stop immunosuppressive medications and not have rejection of the grafted organ. Unfortunately, it is not yet known who those fortunate individuals are, or exactly why it occurs, and so it cannot be predicted. Some other recipients will have a relatively quick response of acute rejection, which can be recognized, but may still result in loss of the graft. However, most recipients will simply intermittently take the immunosupression, resulting in a smoldering chronic rejection. This can also ultimately result in graft failure.

4. Adolescents are particularly prone to non-adherence with medical advice. This is partly due to the developmentally appropriate questioning of authority, and desire to make their own decisions. It is also due to what we now know is immaturity of the prefrontal cortex, resulting in poor judgment in emotionally charged situations. The issues of transitions of care, discussed above, contribute to adolescent non-adherence.

Usual interventions, such as education about the consequences of non-adherence, are ineffective at changing behavior in some adolescents. More intensive interventions such as reminder cell calls or texts might be successful, but would be unnecessary and expensive to do with all recipients. However, targeting those for interventions has been difficult. Several studies have demonstrated that clinicians are not effective in predicting or identifying those pediatric recipients who are or will be non-adherent. Studies using self-report, pilling-counting, and computerized pill bottle tops have not been able to predict who will have biopsy proven rejection (51).

Studies with tacrolimus levels in pediatric liver transplant recipients have identified one promising possibility. Three programs have found that the standard deviation between at least 
three routine blood levels can be used to differentiate those who will have biopsy proven rejection from those who will not (52). This has been replicated demonstrating that intermittent use of immunosuppression is seen in these widely varying levels (53). Interventions to help decrease nonadherence have been piloted, including one using text-messaging to remind teens to take their medication (54) and targeted interventions with those who have high fluctuations in tacrolimus levels (55) or symptoms of posttraumatic stress (56).

\section{Posttraumatic stress}

In recent years it has been found that life-threatening illness and the painful and invasive interventions which are often required, can be experienced as traumatic, resulting in symptoms of Posttraumatic Stress Disorder, in adults (57), children(58), and parents(59,60). A study of the primary caregivers of 170 pediatric liver, heart and kidney transplant recipients found that they did not differ significantly from a healthy comparison group in terms of anxiety or from clinical norms for depression. However, $27.1 \%$ of the parents met criteria for a diagnosis of Posttraumatic Stress Disorder (PTSD) one to three years after successful transplantation (59). Another study of 52 parents of pediatric heart transplant recipients had somewhat similar results, with ten of the 52 reporting symptoms consitant with a diagnosis of $\operatorname{PTSD}(60)$. In a study of 104 adolescent recipients of liver, heart or kidney transplants, at least one year posttransplant, 16\% met all symptoms criteria for PTSD (58).

\section{Long-term quality of life}

Quality of life is difficult to assess in young children, and measures differ significantly between those used with children and with adolescents. However, long-term quality of life in adults who had solid organ transplants as children or adolescents is generally quite favorable. The majority of data are from kidney, liver and heart transplantation. Children have been able to resume growing, return to school, and report that they are relatively physically, socially and psychologically healthy (66). Pediatric organ transplant survivors' reports are consistent with a better quality of life than others with chronic illness, including people on dialysis for renal failure, but not as good a quality of life as healthy controls. However, long-term effects of immunosuppressive medication are a significant problem, and are the major predictor of perceived quality of life. These range from minor issues, such as vaccinations (67), to moderate issues, such as infections $(68,69)$, to life-threatening issues, such as renal failure $(70)$ or cancer (71).

Neuropsychological studies of pediatric organ transplant recipients suggest that not all of the neuropsychological sequellae of renal, cardiac, or liver failure are reversible. A recent review reported normal intelligence, but significantly impaired gross and fine motor skills in schoolaged kidney transplant recipients and that $27 \%$ of liver transplant recipients who had chronic liver disease in early infancy had intelligence scores that were more than 2 standard deviations below test norms (38). In one study pediatric heart transplant recipients had a mean overall IQ of $86.7,46 \%$ had low scores on expressive language, $63 \%$ had visual-motor deficits and $48 \%$ had fine motor deficits (39). These deficits can obviously present problems for school, both before and after the transplant (40).

\section{Later complications of transplantation}

Malignancy, sepsis, and posttransplant lymphoproliferative disorder account for more than $65 \%$ of deaths occurring more than 1 year after pediatric liver transplantation (72). Risk of cancer in kidney transplant recipients has been found to have significantly increased incidence at 25 sites, with risk exceeding 3-fold at 18 of these sites. Most of these cancers were of known or suspected viral etiology (73). Post-transplant lymphoproliferative disorder (PTLD) occurs in 1-20\% of organ recipients following solid organ transplantation (74). It can manifest as 
anything from a benign infectious mononucleosis-like illness to non-Hodgkin's lymphomas with nodal and extranodal site involvement, with a death rate as high as 33\% (75). PTLD risk factors include recipient pretransplant Epstein-Barr virus (EBV) negative serostatus, type of transplant, intensity of immunosuppression, and age (76). To prevent PTLD, minimizing immunosuppression burden and using antiviral agents active against EBV are useful strategies. PTLD treatment may require reduction of immunosuppression, radiation, surgical excision, monoclonal antibodies, interferon-alfa, and chemotherapy (77).

\section{Pregnancy post-transplant}

The first person to become pregnant after a solid organ transplant was a 21 year old woman in 1956 who had received a kidney from her identical twin sister (4). Most of the pregnancies which have been followed in individuals post-transplant have been after kidney transplants, but there are data now on pregnancies post liver transplant (78). There do not seem to be significant structural problems in carrying a pregnancy despite the presence of an abdominal kidney (the original kidneys are usually not removed during a kidney transplant, and the allograft is placed in the abdomen rather than the pelvis). Although some immunosuppression is a normal part of pregnancy, transplant recipients must continue to take immunosuppressive medications during pregnancy. Long-term follow-up suggest that the rate of learning disabilities, attention deficit disorder, and malformations is no higher than in the general population in children born to mothers treated with cyclosporine, azathioprine, or prednisone (4). There is as yet fairly limited long-term information on pregnancy outcomes of recipients on tacrolimus or sirolimus (78).

\section{Future directions}

As immunosuppression improves, increasingly complex transplants are being attempted. There have now been reports of successful transplantation of the face (79) and of the hand (80). Although the surgical techniques are already well developed, very few programs are attempting theses procedures in the United States, and it is unlikely that either of these will be attempted soon for children or adolescents. The immunosuppressant regimen is still not well established. This is critical, because, unlike most solid organ transplants, face or hand transplants are not done to treat a life-threatening condition. It is therefore harder to ethically justify exposure of the recipient to potentially toxic drugs and to the risks of being immunocompromised (81). From a psychiatric standpoint a disfigured face or missing hand presents major problems in terms of identity, self-image and quality of life. However, such visible types of transplantation also present challenges. In addition, these complex transplants require a great deal of rehabilitation to successfully use the new part. Although the recipient of a new hand will not be as ill as someone receiving a new liver, the level of adherence and commitment to frequent and intense rehabilitation regimens is much greater for the hand, at least initially (81). The loss of the graft is also not equivalent to the loss of life. These types of issues will be confronting child psychiatrists in the not so distant future.

\section{Summary}

Solid organ transplantation has become highly successful for children with kidney, liver or heart failure, and is becoming increasingly successful for end-stage pulmonary and intestinal diseases. Psychiatric challenges include consultation to transplant teams regarding candidate selection, support for families during the wait for transplant, enhancing adherence to medication post-transplant, and addressing long-term problems such as posttraumatic stress responses. New ethical challenges are on the horizon, as transplantation moves to organs critical for psychological well-being but not for survival, such as faces and hands. A clear understanding of the developmental and family aspects of transplantation are necessary as child 
and adolescent psychiatrists attempt to keep up with the growing number of immunosuppressive drugs and approaches to the pediatric transplant recipient.

\section{Acknowledgments}

This work was supported in part by a grant from the Astellas Company (PI: Margaret L. Stuber, M.D.), and by a grant from the Maternal and Child Health Bureau (Title V, Social Security Act), Health Resources and Services Administration, Department of Health and Human Services (R40 MC00120) (PI: Margaret L. Stuber, M.D.)

\section{References}

1. Sweet, SC. Pediatric lung transplantation; Proc Am Thorac Soc. 2009 Jan 15. p. 122-127.http://www.unos.org/Data/ downloaded 1 /18/ 2010

2. Woodroffe R, Yao GL, Meads C, Bayliss S, Ready A, Raftery J, Taylor RS. Clinical and costeffectiveness of newer immunosuppressive regimens in renal transplantation: a systematic review and modelling study. Health Technol Assess 2005 May;9(21):1-179. iii-iv. [PubMed: 15899149]

3. Sarwal M, Pascual J. Immunosuppression minimization in pediatric transplantation. Am J Transplant 2007 Oct;7(10):2227-2235. Epub 2007 Aug 16. [PubMed: 17711553]

4. Armenti VT, Constantinescu S, Moritz MJ, Davison JM. Pregnancy after transplantation. Transplant Rev (Orlando) 2008 Oct;22(4):223-240. Epub 2008 Aug 6. [PubMed: 18693108]

5. Asberg A, Midtvedt K, Line PD, Narverud J, Holdaas H, Jenssen T, Reisaeter AV, Johnsen LF, Fauchald P, Hartmann A. Calcineurin inhibitor avoidance with daclizumab, mycophenolate mofetil, and prednisolone in DR-matched de novo kidney transplant recipients. Transplantation $2006 \mathrm{Jul}$ 15;82 (1):62-68. [PubMed: 16861943]

6. Dell-Olio D, Kelly DA. Calcineurin inhibitor minimization in pediatric liver allograft recipients. Pediatr Transplant 2009 Sep;13(6):670-681. Epub 2009 Apr 7. [PubMed: 19413716]

7. Flechner SM, Kobashigawa J, Klintmalm G. Calcineurin inhibitor-sparing regimens in solid organ transplantation: focus on improving renal function and nephrotoxicity. Clin Transplant 2008 Jan-Feb; 22(1):1-15. [PubMed: 18217899]

8. Gibelli NE, Tannuri U, Pinho-Apezzato ML, Tannuri AC, Maksoud-Filho JG, Andrade WC, Velhote MC, Santos MM, Ayoub AA, Marques da Silva M. Sirolimus in pediatric liver transplantation: a singlecenter experience. Transplant Proc 2009 Apr;41(3):901-903. [PubMed: 19376384]

9. Sarwal MM. Out with the old, in with the new: immunosuppression minimization in children. Curr Opin Organ Transplant 2008 Oct;13(5):513-521. [PubMed: 19060535]

10. Cecka JM. The OPTN/UNOS Renal Transplant Registry. Clin Transpl 2005:1-16. [PubMed: 17424721]

11. Cecka JM. Kidney transplantation in the United States. Clin Transpl 2008:1-18. [PubMed: 19711510]

12. Knoll G. Trends in kidney transplantation over the past decade. Drugs 2008;68:3-10. [PubMed: $18442296]$

13. Traum AZ, Ko DS, Kawai T. The potential for tolerance in pediatric renal transplantation. Curr Opin Organ Transplant 2008 Oct;13(5):489-494. [PubMed: 19060531]

14. Gruessner AC, Sutherland DE. Pancreas transplant outcomes for United States (US) cases as reported to the United Network for Organ Sharing (UNOS) and the International Pancreas Transplant Registry (IPTR). Clin Transpl 2008:45-56. [PubMed: 19708445]

15. Sutherland SM, Alexander SR, Sarwal MM, Berquist WE, Concepcion W. Combined liver-kidney transplantation in children: indications and outcome. Pediatr Transplant 2008 Dec;12(8):835-846. [PubMed: 19000066]

16. Bucuvalas JC, Alonso E. Long-term outcomes after liver transplantation in children. Curr Opin Organ Transplant 2008 Jun;13(3):247-251. [PubMed: 18685311]

17. Spada M, Riva S, Maggiore G, Cintorino D, Gridelli B. Pediatric liver transplantation. World J Gastroenterol 2009 Feb 14;15(6):648-674. [PubMed: 19222089]

18. Chan KL, Fan ST, Lo CM, Wei WI, Ng RW, Chung HY, Ng KK, Chan SC, Chan KW, Tso WK, Tsoi NS, Tam PK, Wong J. Pediatric liver transplantation in Hong Kong-a domain with scarce deceased donors. J Pediatr Surg 2009 Dec;44(12):2316-2321. [PubMed: 20006017] 
19. Hong JC, Yersiz H, Farmer DG, Duffy JP, Ghobrial RM, Nonthasoot B, Collins TE, Hiatt JR, Busuttil RW. Long-term outcomes for whole and segmental liver grafts in adult and pediatric liver transplant recipients: a 10-year comparative analysis of 2,988 cases. J Am Coll Surg 2009 May;208(5):682689. discussion 689-91. Epub 2009 Mar 26. [PubMed: 19476815]

20. Brown RS, Belton AM, Martin JM, Simmons DD, Taylor GJ, Willard E. Evolution of quality at the Organ Center of the Organ Procurement and Transplantation Network/United Network for Organ Sharing. Prog Transplant 2009 Sep;19(3):221-226. [PubMed: 19813483]

21. Hornick P, Rose M. Chronic rejection in the heart. Methods Mol Biol 2006;333:131-144. [PubMed: 16790849]

22. Rahmani M, Cruz RP, Granville DJ, McManus BM. Allograft vasculopathy versus atherosclerosis. Circ Res 2006 Oct 13;99(8):801-815. [PubMed: 17038650]

23. Raichlin E, Bae JH, Kushwaha SS, Lennon RJ, Prasad A, Rihal CS, Lerman A. Inflammatory burden of cardiac allograft coronary atherosclerotic plaque is associated with early recurrent cellular rejection and predicts a higher risk of vasculopathy progression. Am Coll Cardiol 2009 Apr 14;53 (15):1279-1286.

24. Morton J, Glanville AR. Lung transplantation in patients with cystic fibrosis. Semin Respir Crit Care Med 2009 Oct;30(5):559-568. Epub 2009 Sep 16. [PubMed: 19760543]

25. Sweet SC. Pediatric lung transplantation. Proc Am Thorac Soc 2009 Jan 15;6(1):122-127. [PubMed: 19131537]

26. Grady RM, Gandhi S, Sweet SC, Mao J, Huddleston CB. Dismal lung transplant outcomes in children with tetralogy of Fallot with pulmonary atresia compared to Eisenmenger syndrome or pulmonary vein stenosis. J Heart Lung Transplant 2009 Nov;28(11):1221-1225. Epub 2009 Sep 26. [PubMed: 19783168]

27. Kirk R, Edwards LB, Aurora P, Taylor DO, Christie JD, Dobbels F, Kucheryavaya AY, Rahmel AO, Stehlik J, Hertz MI. Registry of the international society for heart and lung transplantation: twelfth official pediatric heart transplantation report-2009. J Heart Lung Transplant 2009 Oct;28(10):9931006. [PubMed: 19782282]

28. Aurora P, Edwards LB, Christie JD, Dobbels F, Kirk R, Rahmel AO, Stehlik J, Taylor DO, Kucheryavaya AY, Hertz MI. Registry of the international society for heart and lung transplantation: twelfth official pediatric lung and heart/lung transplantation report-2009. J Heart Lung Transplant 2009 Oct;28(10):1023-1030. [PubMed: 19782284]

29. Vianna RM, Mangus RS. Present prospects and future perspectives of intestinal and multivisceral transplantation. Curr Opin Clin Nutr Metab Care 2009 May;12(3):281-286. [PubMed: 19357509]

30. Mazariegos GV, Squires RH, Sindhi RK. Current perspectives on pediatric intestinal transplantation. Curr Gastroenterol Rep 2009 Jun;11(3):226-233. [PubMed: 19463223]

31. Mazariegos GV. Intestinal transplantation: current outcomes and opportunities. Curr Opin Organ Transplant 2009 Oct;14(5):515-521. [PubMed: 19623070]

32. Hauser GJ, Kaufman SS, Matsumoto CS, Fishbein TM. Pediatric intestinal and multivisceral transplantation: a new challenge for the pediatric intensivist. Intensive Care Med 2008 Sep;34(9): 1570-1579. [PubMed: 18500426]

33. Vianna RM, Mangus RS, Tector AJ. Current status of small bowel and multivisceral transplantation. Adv Surg 2008;42:129-150. [PubMed: 18953814]

34. Telles-Correia D, Barbosaa A, Megaa I, Monteiroa E. Adherence Correlates in Liver Transplant Candidates Transplantation Proceedings 2009;41(5):1731-1734.

35. Fung E, Shaw RJ. Pediatric Transplant Rating Instrument - a scale for the pretransplant psychiatric evaluation of pediatric organ transplant recipients. Pediatr Transplant 2008 Feb;12(1):57-66. [PubMed: 18186890]

36. Shemesh E, Annunziato RA, Yehuda R, Shneider BL, Newcorn JH, Hutson C, Cohen JA, Briere J, Gorman JM, Emre S. Childhood abuse, nonadherence, and medical outcome in pediatric liver transplant recipients. J Am Acad Child Adolesc Psychiatry 2007 Oct;46(10):1280-1289. [PubMed: 17885569]

37. DeMaso DR, Douglas Kelley S, Bastardi H, O'Brien P, Blume ED. The longitudinal impact of psychological functioning, medical severity, and family functioning in pediatric heart transplantation. J Heart Lung Transplant 2004 Apr;23(4):473-480. [PubMed: 15063408] 
38. Melnyk BM, Alpert-Gillis L, Feinstein NF, Crean HF, Johnson J, Fairbanks E, Small L, Rubenstein J, Slota M, Corbo-Richert B. Creating opportunities for parent empowerment: program effects on the mental health/coping outcomes of critically ill young children and their mothers. Pediatrics 2004 Jun;113(6):e597-e607. [PubMed: 15173543]

39. Green A, Meaux J, Huett A, Ainley K. Constantly responsible, constantly worried, constantly blessed: parenting after pediatric heart transplant. Prog Transplant 2009 Jun;19(2):122-127. [PubMed: 19588661]

40. DeMaso DR, Gonzalez-Heydrich J, Erickson JD, Grimes VP, Strohecker C. The experience journal: a computer-based intervention for families facing congenital heart disease. J Am Acad Child Adolesc Psychiatry 2000 Jun;39(6):727-734. [PubMed: 10846307]

41. Burra P, De Bona M. Quality of life following organ transplantation. Transpl Int 2007 May;20(5): 397-409. [PubMed: 17403143]

42. Green A, McSweeney J, Ainley K, Bryant J. In my shoes: children's quality of life after heart transplantation. Prog Transplant 2007 Sep;17(3):199-207. [PubMed: 17944159]

43. Shemesh E, Annunziato RA, Shneider BL, Newcorn JH, Warshaw JK, Dugan CA, Gelb BD, Kerkar N, Yehuda R, Emre S. Parents and clinicians underestimate distress and depression in children who had a transplant. Pediatr Transplant 2005 Oct;9(5):673-679. [PubMed: 16176429]

44. Shemesh E. Assessment and management of psychosocial challenges in pediatric liver transplantation. Liver Transpl 2008 Sep;14(9):1229-1236. [PubMed: 18756465]

45. Annunziato RA, Emre S, Shneider B, Barton C, Dugan CA, Shemesh E. Adherence and medical outcomes in pediatric liver transplant recipients who transition to adult services. Pediatr Transplant 2007 Sep;11(6):608-614. [PubMed: 17663682]

46. Annunziato RA, Parkar S, Dugan CA, Barsade S, Arnon R, Miloh T, Iyer K, Kerkar N, Shemesh E. Brief Report: Deficits in Health Care Management Skills Among Adolescent and Young Adult Liver Transplant Recipients Transitioning to Adult Care Settings. J Pediatr Psychol. 2009 Dec 7;

47. McDonagh JE. Growing up and moving on: transition from pediatric to adult care. Pediatr Transplant 2005 Jun;9(3):364-372. [PubMed: 15910395]

48. Annunziato RA, Emre S, Shneider BL, Dugan CA, Aytaman Y, McKay MM, Shemesh E. Transitioning health care responsibility from caregivers to patient: a pilot study aiming to facilitate medication adherence during this process. Pediatr Transplant 2008 May;12(3):309-315. [PubMed: 18435606]

49. Dew MA, Dabbs AD, Myaskovsky L, Shyu S, Shellmer DA, DiMartini AF, Steel J, Unruh M, Switzer GE, Shapiro R, Greenhouse JB. Meta-analysis of medical regimen adherence outcomes in pediatric solid organ transplantation. Transplantation 2009 Sep 15;88(5):736-746. [PubMed: 19741474]

50. Telles-Correia D, Barbosa A, Mega I, Monteiro E. Adherence correlates in liver transplant candidates. Transplant Proc 2009 Jun;41(5):1731-1734. [PubMed: 19545717]

51. Shemesh E, Shneider BL, Savitzky JK, Arnott L, Gondolesi GE, Krieger NR, Kerkar N, Magid MS, Stuber ML, Schmeidler J, Yehuda R, Emre S. Medication adherence in pediatric and adolescent liver transplant recipients. Pediatrics 2004 Apr;113(4):825-832. [PubMed: 15060234]

52. Stuber ML, Shemesh E, Seacord D, Washington J 3rd, Hellemann G, McDiarmid S. Evaluating nonadherence to immunosuppressant medications in pediatric liver transplant recipients. Pediatr Transplant 2008 May;12(3):284-288. [PubMed: 18331387]

53. Dobbels F, Van Damme-Lombaert R, Vanhaecke J, De Geest S. Growing pains: non-adherence with the immunosuppressive regimen in adolescent transplant recipients. Pediatr Transplant 2005 Jun;9 (3):381-390. [PubMed: 15910397]

54. Miloh T, Annunziato R, Arnon R, Warshaw J, Parkar S, Suchy FJ, Iyer K, Kerkar N. Improved adherence and outcomes for pediatric liver transplant recipients by using text messaging. Pediatrics 2009 Nov;124(5):e844-e850. [PubMed: 19822583]

55. Shemesh E, Annunziato RA, Shneider BL, Dugan CA, Warshaw J, Kerkar N, Emre S. Improving adherence to medications in pediatric liver transplant recipients. Pediatr Transplant 2008 May;12(3): 316-323. [PubMed: 18435607]

56. Shemesh E, Lurie S, Stuber ML, Emre S, Patel Y, Vohra P, Aromando M, Shneider BL. A pilot study of posttraumatic stress and nonadherence in pediatric liver transplant recipients. Pediatrics $2000 \mathrm{Feb}$; 105(2):E29. [PubMed: 10654989] 
57. Shemesh E, Yehuda R, Milo O, Dinur I, Rudnick A, Vered Z, Cotter G. Posttraumatic stress, nonadherence, and adverse outcome in survivors of a myocardial infarction. Psychosom Med 2004 Jul-Aug;66(4):521-526. [PubMed: 15272097]

58. Mintzer LL, Stuber ML, Seacord D, Castaneda M, Mesrkhani V, Glover D. Traumatic stress symptoms in adolescent organ transplant recipients. Pediatrics 2005 Jun;115(6):1640-1644. [PubMed: 15930227]

59. Young GS, Mintzer LL, Seacord D, Castañeda M, Mesrkhani V, Stuber ML. Symptoms of posttraumatic stress disorder in parents of transplant recipients: incidence, severity, and related factors. Pediatrics 2003 Jun;111(6 Pt 1):e725-e731. [PubMed: 12777592]

60. Farley LM, DeMaso DR, D'Angelo E, Kinnamon C, Bastardi H, Hill CE, Blume ED, Logan DE. Parenting stress and parental post-traumatic stress disorder in families after pediatric heart transplantation. J Heart Lung Transplant 2007 Feb;26(2):120-126. [PubMed: 17258144]

61. Kaller T, Boeck A, Sander K, Richterich A, Burdelski M, Ganschow R, Schulz KH. Cognitive abilities, behaviour and quality of life in children after liver transplantation. Pediatr Transplant. 2010 Jan 7;

62. Prelog M, Zimmerhackl LB. Varicella vaccination in pediatric kidney and liver transplantation. Pediatr Transplant 2010 Feb;14(1):41-47. [PubMed: 20091941]

63. Fonseca-Aten M, Michaels MG. Infections in pediatric solid organ transplant recipients. Semin Pediatr Surg 2006 Aug;15(3):153-161. [PubMed: 16818136]

64. Kotton CN. Update on infectious diseases in pediatric solid organ transplantation. Curr Opin Organ Transplant 2008 Oct;13(5):500-505. [PubMed: 19060533]

65. Mueller-Ehmsen J, Schmid C, Vogeser M, Koch KC, Reichenspurner H, Daebritz S, Meiser B, Reichart B. VENINAHTx-Investigators. Mycophenolate and sirolimus as calcineurin inhibitor-free immunosuppression improves renal function better than calcineurin inhibitor-reduction in late cardiac transplant recipients with chronic renal failure. Transplantation 2009 Mar 15;87(5):726-733. [PubMed: 19295318]

6671. Groetzner J, Kaczmarek I, Schulz U, Stegemann E, Kaiser K, Wittwer T, Schirmer J, Voss M, Strauch J, Wahlers T, Sohn HY, Wagner F, Tenderich G, Stempfle HU, Vajdic CM, van Leeuwen MT. Cancer incidence and risk factors after solid organ transplantation. Int J Cancer 2009 Oct 15;125(8):1747-1754. [PubMed: 19444916]

67. Alonso EM, Sorensen LG. Cognitive development following pediatric solid organ transplantation Curr Opin Organ Transplant 2009 Oct;14(5):522-525.

68. Uzark K, Spicer R, Beebe DW. Neurodevelopmental outcomes in pediatric heart transplant recipients. J Heart Lung Transplant 2009 Dec;28(12):1306-1311. Epub 2009 Sep 26. [PubMed: 19782596]

69. Weil CM, Rodgers S, Rubovits S. School re-entry of the pediatric heart transplant recipient. Pediatr Transplant 2006 Dec;10(8):928-933. [PubMed: 17096760]

70. Bucuvalas J. Long-term outcomes in pediatric liver transplantation. Liver Transpl 2009 Nov; 15:S6S11. [PubMed: 19877291]

71. Vajdic CM, McDonald SP, McCredie MR, van Leeuwen MT, Stewart JH, Law M, Chapman JR, Webster AC, Kaldor JM, Grulich AE. Cancer incidence before and after kidney transplantation. JAMA 2006 Dec 20;296(23):2823-2831. [PubMed: 17179459]

72. Ohta H, Fukushima N, Ozono K. Pediatric post-transplant lymphoproliferative disorder after cardiac transplantation. Int J Hematol 2009 Sep;90(2):127-136. Epub 2009 Aug 12. [PubMed: 19669857]

73. Uribe M, Hunter B, Alba A, Calabrán L, Flores L, Soto P, Herzog C. Posttransplant lymphoproliferative disorder in pediatric liver transplantation. Transplant Proc 2009 Jul-Aug;41(6): 2679-2681. [PubMed: 19716000]

74. Lim WH, Russ GR, Coates PT. Review of Epstein-Barr virus and post-transplant lymphoproliferative disorder post-solid organ transplantation. Nephrology (Carlton) 2006 Aug;11(4):355-366. [PubMed: 16889577]

75. Schubert S, Renner C, Hammer M, Abdul-Khaliq H, Lehmkuhl HB, Berger F, Hetzer R, Reinke P. Relationship of immunosuppression to Epstein-Barr viral load and lymphoproliferative disease in pediatric heart transplant patients. Heart Lung Transplant 2008 Jan;27(1):100-105. 
76. Coffin CS, Shaheen AA, Burak KW, Myers RP. Pregnancy outcomes among liver transplant recipients in the United States: a nationwide case-control analysis. Liver Transpl 2010 Jan;16(1):5663. [PubMed: 20035524]

77. Siemionow M, Papay F, Alam D, Bernard S, Djohan R, Gordon C, Hendrickson M, Lohman R, Eghtesad B, Coffman K, Kodish E, Paradis C, Avery R, Fung J. Near-total human face transplantation for a severely disfigured patient in the USA. Lancet 2009 Jul 18;374(9685):203-209. Epub 2009 Jul 14. [PubMed: 19608265]

78. Ravindra KV, Buell JF, Kaufman CL, Blair B, Marvin M, Nagubandi R, Breidenbach WC. Hand transplantation in the United States: experience with 3 patients. Surgery 2008 Oct;144(4):638-643. discussion 643-4. [PubMed: 18847649]

79. Gordon CR, Siemionow M. Requirements for the development of a hand transplantation program Ann Plast Surg 2009 Sep;63(3):262-273. 


\section{Table 1}

One year survival by age at transplant

\begin{tabular}{|l|l|l|l|l|}
\hline & $<\mathbf{1}$ year & $\mathbf{1 - 5}$ years & $\mathbf{6 - 1 0}$ & $\begin{array}{c}\mathbf{1 1 -} \\
\mathbf{1 7}\end{array}$ \\
\hline Heart & 82.8 & 85.9 & 86.8 & 89.7 \\
\hline Liver & 81.1 & 78.1 & 84.4 & 87.4 \\
\hline Kidney & $*$ & 92.7 & 94.7 & 94.1 \\
\hline Intestine & 63.8 & 75.6 & 66.7 & 80.0 \\
\hline Lung & $*$ & $*$ & 88.0 & 78.0 \\
\hline
\end{tabular}

Data from a graph from the Organ Procurement and Transplantation Network All Kaplan-Meier Graft Survival Rates For Transplants Performed : 1997 - 2004 Based on OPTN data as of January 8, 2010.

* Denotes a Graft Survival was not computed due to N less than 10. 1 year survival based on 2002-2004 transplants, 3 year survival based on 19992002 transplants, 5 year survival based on 1997-2000 transplants. 
Table 2

Five year survival by age at transplant

\begin{tabular}{|l|l|l|l|l|}
\hline & $<\mathbf{1}$ year & $\mathbf{1 - 5}$ years & $\mathbf{6 - 1 0}$ & $\begin{array}{l}\mathbf{1 1 -} \\
\mathbf{1 7}\end{array}$ \\
\hline Heart & 68.0 & 71.1 & 75.1 & 67.8 \\
\hline Liver & 66.9 & 75.31 & 67.0 & 64.2 \\
\hline Kidney & 100 & 84.2 & 82.2 & $*$ \\
\hline Intestine & 30.8 & 34.7 & 69.2 & $*$ \\
\hline Lung & $*$ & $*$ & 40.7 & 34.6 \\
\hline
\end{tabular}

Data from a graph from the Organ Procurement and Transplantation Network All Kaplan-Meier Graft Survival Rates For Transplants Performed : 1997 - 2004 Based on OPTN data as of January 8, 2010.

* Denotes a Graft Survival was not computed due to N less than 10. 1 year survival based on 2002-2004 transplants, 3 year survival based on 19992002 transplants, 5 year survival based on 1997-2000 transplants. 